\title{
THERMAL ANALYSIS OF DRY STORAGE AND TRANSPORTATION CASKS CASTOR USING COBRA-SFS
}

\author{
Martin ŠeveČeK ${ }^{a, b, *}$, Mojmír VAlach ${ }^{a}$, Chih-Hao LeE ${ }^{b}$ \\ ${ }^{a}$ Czech Technical University in Prague, Faculty of Nuclear Sciences and Physical Engineering, Department of \\ Nuclear Reactors, V Holešovickách 2, 18000 Prague 8, Czech Republic \\ ${ }^{b}$ National Tsing Hua University, Institute of Nuclear Engineering and Science, No. 101, Section 2, Guangfu \\ Road, East District, Hsinchu City, Taiwan 300 \\ * corresponding author: martin. sevecek@fjfi.cvut.cz
}

\begin{abstract}
State Office for Nuclear Safety is a regulator body in the Czech Republic handling also licensing of storage and transportation casks (SCs) of the spent nuclear fuel (SNF). One of the main concerns for the dry storage of SNF is the safe removal of the residual heat resulting from the decay of fission products, actinides, and activated construction materials. There are many storage systems in use around the world with different storage configuration, fuel designs and boundary conditions that need to be evaluated. Two thermal models of SNF storage casks CASTOR 440/84 and CASTOR 440/84M were developed using the COBRA-SFS code, which is an internationally accepted and validated code used for licensing of dry storage casks and safety evaluation. The casks are in operation at the Nuclear Power Plant Dukovany for dry storage of the WWER-440 SNF. Both models were validated and used for evaluation of several problems in different configuration and particularly for licensing purposes at the SUJB.
\end{abstract}

KEYwORDS: COBRA-SFS, heat removal system, licensing, spent nuclear fuel, storage and transportation cask, thermal analysis, WWER.

\section{INTRODUCTION}

The accurate prediction of heat transfer and temperature fields in a dry storage cask CASTOR has been undertaken. Due to the nature of the dry storage casks, the temperature cannot be directly controlled and calculations are performed to ensure safe storage and transport of SNF in all postulated conditions during decades of dry SNF storage. Recently, many applicants for a license of storage and transportation cask (also in the Czech Republic) have used Computational Fluid Dynamics (CFD) codes to simulate the thermal behavior of dry storage systems. CFD analysis was mentioned also in the IAEA report [1] or recently performed by $[2-8]$. However, the CFD codes have their limitations and specific problems (errors in spatial discretization, meshing, numerical instability, and high computational power). For that reason, the State Office for Nuclear Safety in the Czech Republic (SUJB) decided to perform confirmatory independent calculations of the thermal behavior of SC CASTOR using COBRA-SFS code [9] in cooperation with Department of Nuclear Reactors, CTU in Prague and UJV Rez as recommended by international standards $[10,11]$. The subchannel code COBRA-SFS based on the well-known COBRA thermohydraulical code has been used for thermal analysis of different systems with PWR, BWR but also WWER fuel geometries [12-16].

The applicant for the license of storage casks for WWER-440 SNF storage [17] supported the applica- tion with CFD thermal analysis using the FLUENT code [18]. The SUJB staff decided to perform an independent evaluation of the heat removal design of the storage casks CASTOR using COBRA-SFS code and to use the models for new potential applications in case of new design changes as well.

\subsection{COBRA-SFS AND CFD CODES}

Several studies concerning safe heat removal from dry storage casks using COBRA-SFS were presented - $[6$, 19-21]. Most of the research and work was conducted more than 20 years ago at the time of validation of the first version of the code. Recently, some institutions (KAIST, EPRI, NPP Paks) have been using this code for comparison or validation of new codes [22, 23].

Other authors published their results and recommendations on the usage of CFD computer codes. Horizontal dry storage systems using PHOENICS code were investigated by [24], other studies showed thermal analysis methods for a vertical concrete SC with PHOENICS and FIT-3D CFD codes [25], there were also practical guidelines for modeling a concrete SC using FLEUNT that were confirmed by experimental data from the VSC-17 SC [26]. The standard review plan NUREG-1536 [27] defined by the US NRC allows applicants to use CFD codes together with the simplified porous media approach and its effective thermal conductivity. However, it recognizes the benefits of using more complex approaches modelling detailed geometry similar to COBRA-SFS. 
The models presented in this paper are based on the detailed description of the inner complex geometries of the dry SCs CASTOR 440/84 and CASTOR 440/84M. Models in the COBRA-SFS code are based on the detailed design and equations defining the heat transfer rather than using a general approach of CFD codes (effective thermal conductivity, porous media, etc.).

The porous media concept adopted in most of the CFD SCs flow calculations usually requires experimental data for determining of effective conductivity. The experimental validation of porous media and fuel effective conductivity models is needed for application of the code, on a case-by-case basis[6]. In contrast, because of the extensive validation of the COBRA-SFS code by comparison with experimental data in single-assembly experiments and test casks loaded with spent fuel (see references [14, 23, 28, 29]), and the fundamental thermal-hydraulic modeling approach used in the code to represent spent fuel assemblies within a cask [30], extensive case-by-case validation is not necessary for each application of the code. The code requires only detailed knowledge of the geometry of the storage system. From this perspective, the model created in COBRA-SFS is suitable for licensing purposes in the Czech Republic. On the other hand, the creation of the model is a much more difficult and time-consuming task than CFD modeling.

\section{LICENSING PROCESS AND REQUIREMENTS IN THE CZECH REPUBLIC}

There were several safety functions of dry spent fuel storage facilities defined. Safety functions must be maintained during normal operation, anticipated operational occurrences, and design basis accident conditions by either the storage cask, the storage facility itself, or both [31].

The detailed requirements are specified in the Atomic Act [32] or other regulatory legal documents. The basic safety functions are illustratively shown in Figure 1 and can be simply summarized as [31]:

- Maintain the subcriticality of stored SNF

- Ensure removal of heat generated by the stored $\mathrm{SNF}$

- Prevent the release of radioactive material

- Maintain retrievability of the SNF throughout the whole lifetime of the storage facility

- Ensure that radiation dose rates and doses do not exceed valid limits

The applicant shall verify by analysis, surveillance, testing, and inspection that the physical status of the installation and its operation continue in accordance with Technical Specifications, safety requirements, and safety assessment. The independent reassessment shall be periodically updated if there are modifications or new regulatory requirements and standards. Each type of SNF SC has to be licensed. However, there are no facility-specific international requirements, but only guidelines exist [33]. This paper focuses on the safe removal of heat from the spent nuclear fuel, however, the design of a SC has to ensure all safety functions.

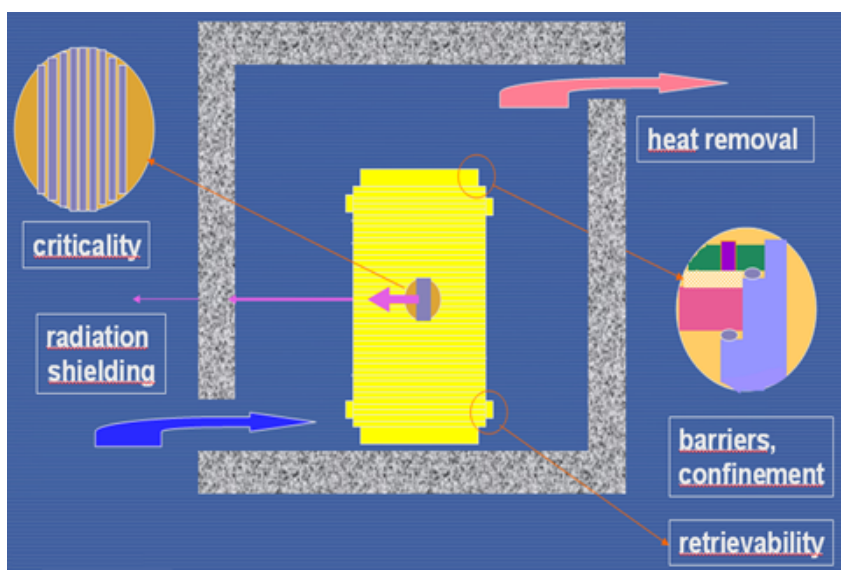

FIGURE 1. Five fundamental safety functions of the dry storage casks as defined by the State Office for Nuclear Safety.

The other characteristics of both SCs are: dry transportation and 60 years storage of the SNF; minimum of 5 years cooling of the SNF before backfilling the SC; SC is filled with helium with low pressure around $700 \mathrm{kPa}$; the basket consists of 84 casings; the central position is empty.

\subsection{DeCAy heat Removal}

At the Storage Facility for Spent Nuclear Fuel Dukovany (SFSNF), the basic (regulatory) heat-related requirements originating from the licensing process of the SCs CASTOR are as follows:

- The peak cladding temperature (PCT) during transport and storage must not exceed $350^{\circ} \mathrm{C}$ [37]

- The total thermal output of all SNF assemblies in one cask must not exceed the limiting value (e.g., $25 \mathrm{~kW}$ for CASTOR440/84) or must not exceed the limits of heat generation for a particular SNF single assembly

- The licensed cask has to be capable of withstanding an external fire for 30 minutes with the temperature of $800^{\circ} \mathrm{C}$

- PCT during the drying process of the SC can exceed $350^{\circ} \mathrm{C}$ only for a limited time.

The thermal evaluation of a SC must also include: definition of the SNF inventory, cask material properties, SNF thermal output, cask loading pattern, operational and accidental conditions, boundary conditions, stationary and transient calculation of temperatures at selected points, compliance with regulatory and design criteria, inputs to emergency procedures, 

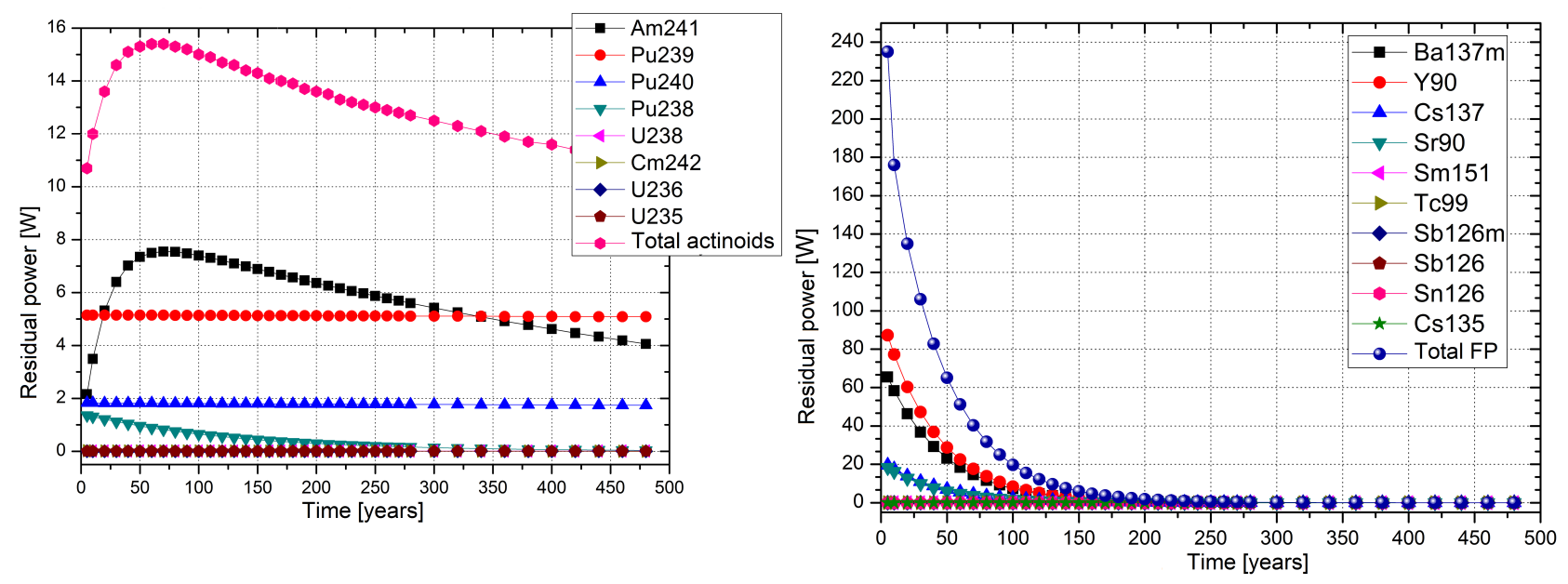

FIGURE 2. Residual heat generated in the WWER SNF by the most significant actinides (left) and fission products (right) for the first 500 years after discharge from a reactor. It was calculated using ORIGEN-ARP decay code, with cross-section libraries generated using 2-D depletion module TRITON from the SCALE package for a reference condition of WWER-440 fuel as recommended by [34-36].

\begin{tabular}{lrr}
\hline PARAMETER & CASTOR 440/84 & CASTOR 440/84M \\
\hline Diameter [mm] & 2660 & 2660 \\
Height [mm] & 4080 & 4170 \\
Thickness of the wall [mm] & 370 & 410 \\
Storage weight [t] & 116.11 & 118.34 \\
Max. activity [Bq] & $2.7 \times 10^{17}$ & $2.6 \times 10^{17}$ \\
Max. D on surface & $<2 \mathrm{mSv} / \mathrm{h}$ & $<2 \mathrm{mSv} / \mathrm{h}$ \\
Max. $\dot{D}$ in 2 m from SC & $<0.1 \mathrm{mSv} / \mathrm{h}$ & $84 \mathrm{mSv} / \mathrm{h}$ \\
Max. number of FAs & 84 & $84.66 \mathrm{~kW}$ \\
Max. residual power of SC - heterogeneous pattern & - & $24.50 \mathrm{~kW}$ \\
Max. residual power of SC - homogeneous pattern & $21 \mathrm{~kW}$ & $-340 \mathrm{~W}(6 \mathrm{x}), 290 \mathrm{~W}(78 \mathrm{x})$ \\
Max. residual power of 1 FA - heterogeneous pattern & $250 \mathrm{~W}$ & $291.7 \mathrm{~W}$ \\
Max. residual power of 1 FA - homogeneous pattern & & \\
\hline
\end{tabular}

TABLE 1. Fundamental parameters of the storage and transportation casks CASTOR 440/84 a 440/84M

derivation of Technical Specifications and thermal assessment of the cask drying procedure [31, 32].

For heat removal calculations, the SNF is defined by the evolution of its residual heat (source term). It was calculated for different cases using ORIGENARP [38] code from the SCALE 6.1 package. The WWER-440 cross section libraries were generated using the $2 \mathrm{D}$ depletion module TRITON from the SCALE package, and a similar approach was validated against isotopic assay experimental data for spent fuel in [35]. An example of residual heat generated by actinides and fission products in one of the WWER-440 SNF assemblies is presented in Figure 2. The evolution of the total generated residual heat for each of the $84 \mathrm{SNF}$ assemblies has been introduced into the COBRA-SFS model as boundary conditions.

\section{Construction of the SCs CASTOR}

There have been two types of storage casks in the Dukovany storage facilities used: CASTOR 440/84 and CASTOR 440/84M. The older - CASTOR $440 / 84$ was licensed by the SUJB in 1995 , and the new modified type - CASTOR 440/84M obtained its original license in 2005. Both licenses were reviewed, and the designs were reassessed several times due to the design changes of WWER fuel and the SC itself. The casks are dual-purpose casks for transportation and storage of 84 FAs of undamaged spent nuclear fuel from reactor WWER-440. Both types of SCs have been developed and produced by German company GNS - Gesellschaft fãijr Nuclear-Service mbH (GNS), headquartered in Essen, Germany. The fundamental characteristics of both SCs are summarized in Table 1.

\subsection{HeAt REMOVAl SYSTEM OF THE SCS}

The cross-section diagram of both types of SCs are illustrated in Figure 3. The residual heat originates mainly from the radioactive decay of fission products and actinides that are presented in the spent fuel pellets. The construction materials of the SNF are also 


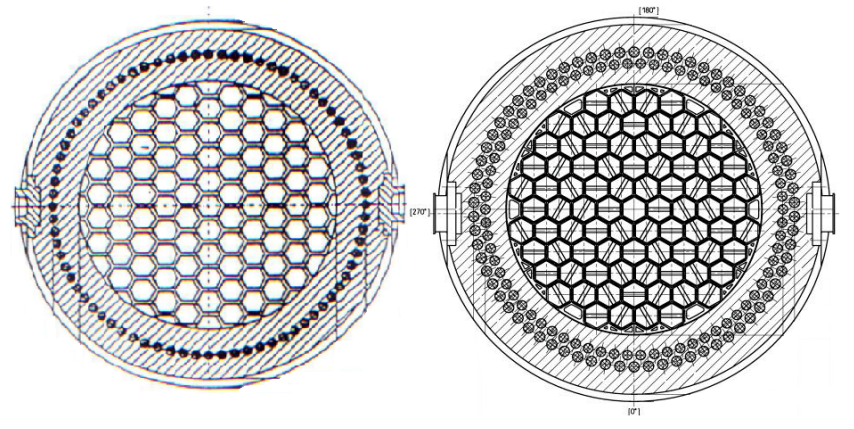

Figure 3. Plain cut in the dual purpose storage and transportation casks CASTOR 440/84 (left) and CASTOR 440/84M (right)

activated and generate considerable heat energy in comparison with fission products and actinides. The heat is transferred from the SNF pellets mainly by conductive heat transfer to the fuel cladding. Radiative heat transfer plays also a role mainly in the heat transfer from the fuel rods to the internal structures of SCs. A SC is filled with helium flowing around SNF, more precisely around the fuel rods. Helium carries the heat away from the SNF using natural convection heat transfer. Helium is circulating inside the cask and is cooled down on the SC's shell inner surface. The heat passes through the cask shell to the outer surface of the SC. The outer surface includes ribs to improve convection heat transfer with the environment. The ambient air convects the residual heat from the SC, and the storage facility itself ventilates the hot air outside.

\subsection{DESIGN DIFFERENCES}

The SCs CASTOR 440/84 and CASTOR 440/84M are very similar in terms of design. There are only a few differences and modifications to accommodate higher burnup fuel. The biggest change is the design of the basket. The improved design for CASTOR 440/84M is using AlMg steel with ATABOR dividers. ATABOR is a special type of steel with a high content of boron for neutron absorption.

The different construction of both baskets is shown in Figure 3. The dimensions of the SNF are the same for both types of SCs. Therefore, the inner dimensions of the basket tubes are the same as well. However, the basket of the CASTOR $440 / 84 \mathrm{M}$ is more compact, and the walls are thicker. The next difference is a new construction of a cask shell. There was an extra row of polyethylene rods added to improve the shielding capability of the cask and the construction of the outer ribs was improved. There are two moderator plates added to the bottom and top of the $\mathrm{SC}$ to improve the neutron shielding in the top and bottom part.

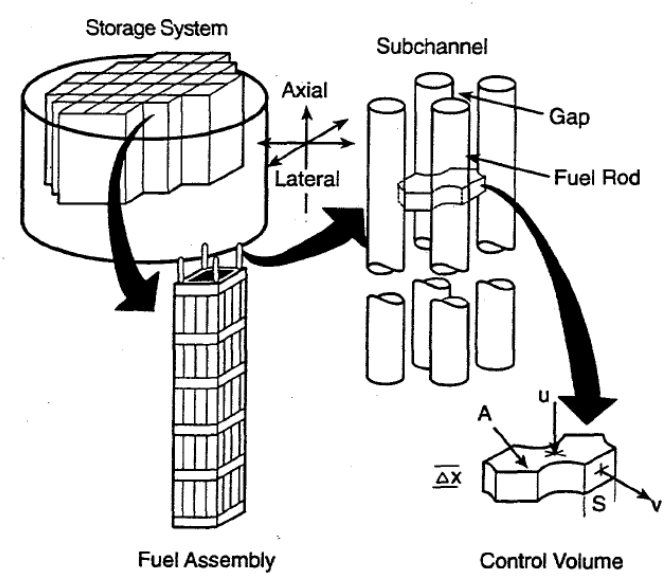

FiguRE 4. Relation of a subchannel control volume to a general SNF storage or transportation system [30]

\section{COBRA-SFS THERMAL MODELS}

\subsection{COBRA-SFS CODE}

COBRA-SFS code [30] is a computer code for the prediction of material temperatures and fluid conditions in various systems for spent fuel storage. It performs thermal-hydraulic analysis and has been successfully validated and verified [19]. COBRA-SFS solves three basic equations in finite volume form: 1) conservation of mass, 2) momentum, and 3) energy. The equations assume an incompressible single-phase heat transfer fluid (typically inert gases). Finite volume method is used also for the calculation of the conduction inside and between the solid structures of the dry storage system which is then coupled to the fluid solution [39].

In COBRA-SFS, the general Eulerian control volume is defined as the fluid subchannel in the rod array. The geometry is illustrated in Figure 4. As can be seen, the fluid flow is constrained by the surface of fuel cladding. On the smaller scale, the fuel rods section the channel into many subchannels that communicate laterally by crossflow. Applying the integral balance relations to the control volume of each subchannel yields a set of subchannel equations which can be approximated in finite difference form and numerically solved.

\subsection{NumERICAL MODELS}

The configuration modeled is a SC filled with SNF standing alone (vertically) inside a dry storage facility Dukovany. The model was simplified using a symmetry of the SC. Only one-sixth was modeled. This is a valid approach because 84 FAs with generally similar characteristics were stored in the SC. If the number of stored FAs is lower and the differences between particular assemblies are bigger, full-scale model needs to be developed (e.g., dry storage of WWER-1000 $\mathrm{SNF}$ ). There are three main areas of interest when modeling using COBRA-SFS: Upper Plenum, Channel Region, and Lower Plenum [19]. The main de- 
tailed modeled section of the $\mathrm{SC}$ is a channel region (basket in this particular case). Plenums provide a one-dimensional mixing node for helium entering or leaving the flow channels and subchannels in the basket region. This model enables the code to directly calculate the "closed loop" natural recirculation of helium gas within a cask or canister. The plenum model also includes the capability of modeling conduction heat transfer paths above and below the basket region. The feature is typically used to represent the solid structures of the cask lid (in the upper plenum), and the cask base (in the lower plenum). there are solid structures around the basket. They are defined by several boundary conditions. Outer shell covering the SC's basket is considered as a plenum as well.

First, models of the WWER-440 fuel assemblies were created. Since only one-sixth of SCs was modeled, models of the half-assemblies were also required. There are two types of nodes used in these models: fuel rods and subchannels around these rods. A simplified sketch of the fuel model with fuel rod numbering is presented in Figure 5. There are 127 fuel rods in 67 groups. In these groups, several fuel rods were merged into one bigger fuel rod. This technique simplified the models and saved computational time. Similar numbering process was used in numbering subchannels around the fuel rods. This approach was developed in the validation work for COBRA-SFS in the 1980âẮs and has been shown to yield accurate predictions of peak temperature and temperature distributions in spent fuel assemblies and casks. However, it requires careful selection of rods with similar decay heat and geometric symmetry within the rod array, to avoid distortion of the temperature distribution within the fuel assembly. If sufficient computational resources are available, a rod-by-rod representation of the fuel assemblies is the preferred approach, as it avoids the flattening of local temperature gradients, that is, the inevitable result of merging adjacent rods.

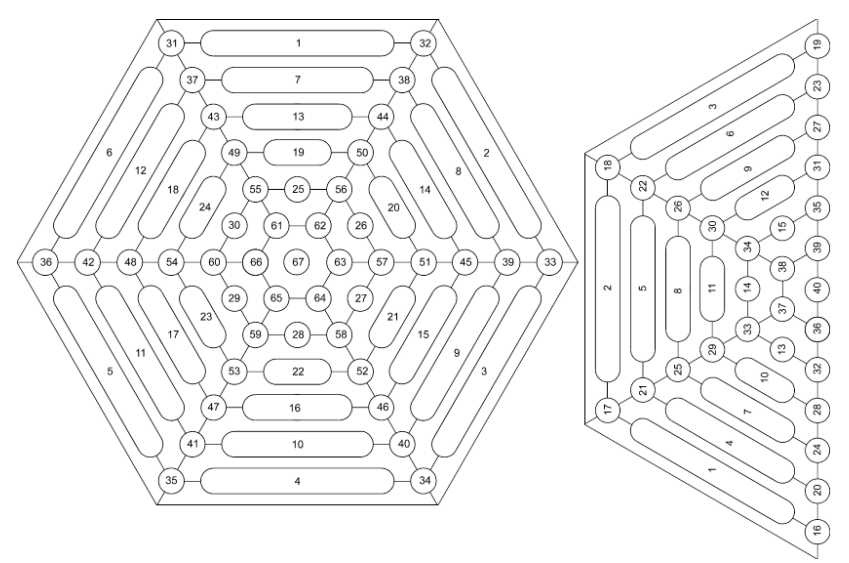

FigURE 5. Illustration of WWER-440 fuel assembly models with fuel rod numbering. Outer fuel rods are merged to simplify the model, fuel rods with potentially higher PCT are modeled individually.
After the definition of fuel assemblies, the design and connections of the SC basket and particular casings were modeled. There are 16 fuel assemblies (12 full assemblies and four halves) incorporated into onesixth of the basket model. Additionally, there are 24 channels without fuel filled only with helium. They substitute the periphery construction of the basket, one represents the central empty position, and the rest are channels around the actual fuel assemblies. The illustration of the computational model and its numbering is shown in Figure 6.

All defined assemblies and channels with or without fuel are connected by 326 solid slabs. 317 slabs connect assemblies inside the basket, and the others represent SC's body construction, shielding, and connection to an environment. The heat transfer models were individually incorporated into the model for all channels and solid slabs.

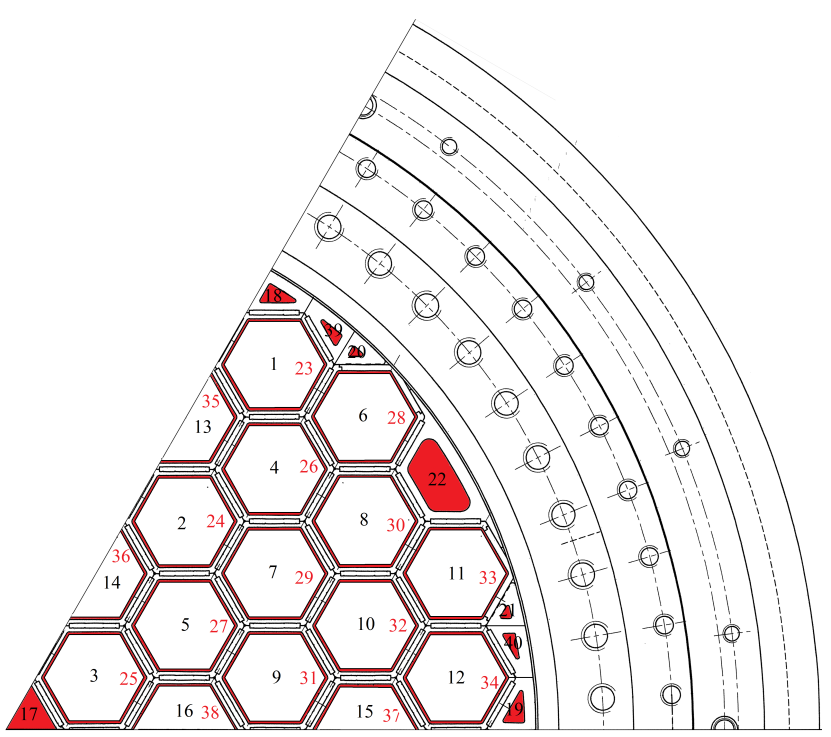

Figure 6. One sixth of the modeled SC with subchannel numbering. There were 12 full-assemblies (No. 1-12), 4 half-assemblies (No. 13-16) and 24 empty channels filled with He (No. 17-40) implemented into the model.

\section{Results}

\subsection{Reference Calculations and Models VALIDATION}

Both storage casks are licensed for storage of the WWER-440 SNF. However, the newer type - CASTOR 440/84M enables to store the SNF with different parameters (e.g., residual heat generation, burnup, uranium enrichment). In the safety documentation provided by the applicant, one reference "boundary" configuration of the SNF (pattern) was approved for CASTOR 440/84 and two patterns for the CASTOR $440 / 84 \mathrm{M}$. The reference loading patterns are illustrated in Figure 7 together with the actual configuration of the SC CASTOR 440/84 No. 10 from the SFSNF Dukovany. 


\begin{tabular}{cccc}
\hline $\begin{array}{c}\text { Temperature sensor No. } \\
{[-]}\end{array}$ & $\begin{array}{c}\text { Measured temperature } \\
{\left[{ }^{\circ} \mathrm{C}\right]}\end{array}$ & $\begin{array}{c}\text { Calculated temperature } \\
{\left[{ }^{\circ} \mathrm{C}\right]}\end{array}$ & $\begin{array}{c}\text { Abs. difference } \\
{[\%]}\end{array}$ \\
\hline 1 & 47.50 & 45.34 & 4.764 \\
2 & 46.91 & 45.34 & 3.463 \\
3 & 58.75 & 63.95 & 8.131 \\
4 & 57.12 & 63.90 & 10.610 \\
5 & 50.88 & 46.64 & 9.091 \\
6 & 24.85 & 24.85 & 0.000 \\
\hline
\end{tabular}

TABLE 2. Comparison of measured temperatures on the SC No. 10 and temperatures calculated by the COBRA-SFS heat-removal model

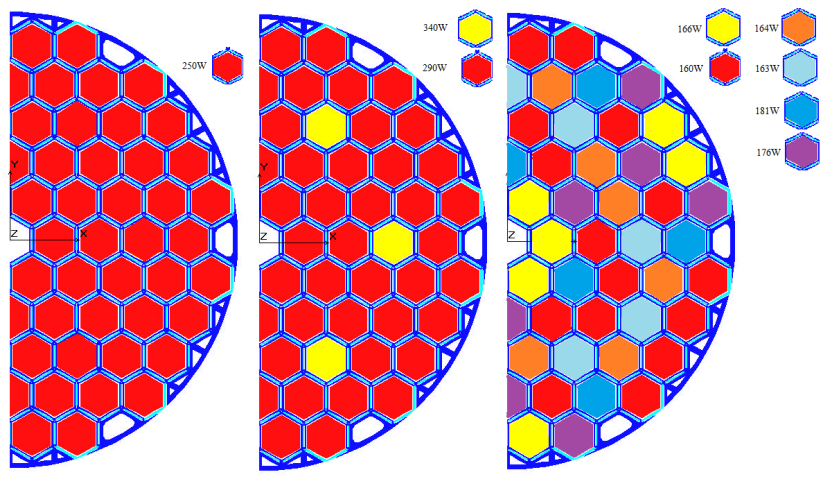

FiguRE 7 . The reference homogeneous pattern for CASTOR 440/84 (left), reference heterogeneous pattern for CASTOR 440/84M (center) and the initial pattern of the real SC CASTOR 440/84 No.10 from the SFSNF (right)

The reference configurations were calculated using COBRA-SFS code and compared with the results provided by the applicant. The applicant used CFD code FLUENT [18] to prove the safe design of the SCs. The results of the reference calculations calculating the PCT are presented in Figure 9. Two reference calculations are presented together with results from the actual SC No.10. The highest peak cladding temperatures are: $255.0^{\circ} \mathrm{C}$ and $256.8^{\circ} \mathrm{C}$ for the two maximal patterns for CASTOR $440 / 84$ and $298^{\circ} \mathrm{C}$ for the reference pattern of the SC CASTOR $440 / 84 \mathrm{M}$. The FLUENT results provided by the applicant are not presented here, but they are similar lower by 3 $5{ }^{\circ} \mathrm{C}$. This is in agreement with other studies where COBRA-SFS is presented as a code providing conservative results [40].

The WWER-440 fuel assembly consists of 127 fuel pins that do not have uniform power peaking. Heat source term was calculated for the whole assembly and radial peaking factors were defined based on the expected radial power profile. The difference when using uniform radial peaking (homogeneous) in an assembly and non-uniform peaking (heterogeneous) with a peaking factor 1.2 is shown in Figure 8. Higher peaking factor results in slightly higher temperatures, but the effect are almost negligible. Therefore, other

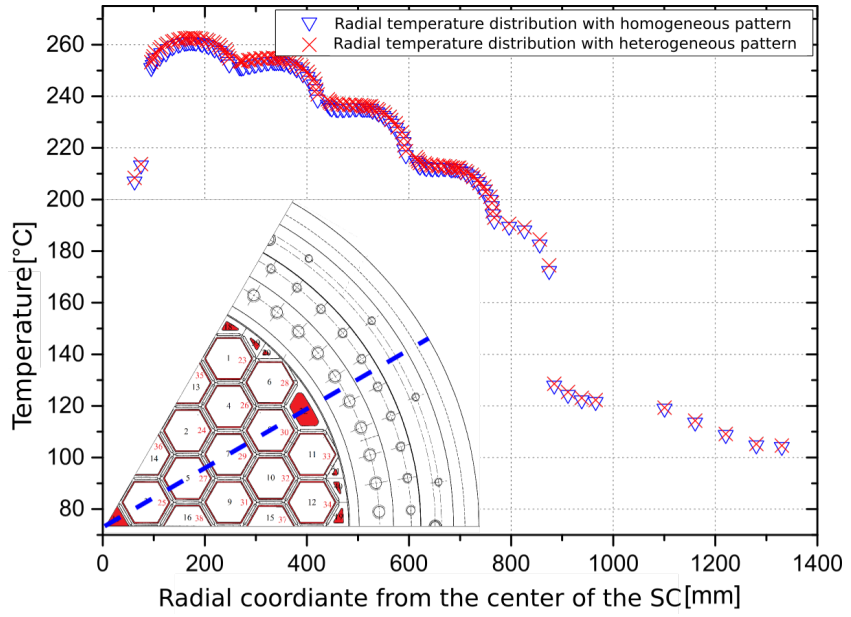

FiguRE 8. Radial temperature distributions for homogeneous and heterogeneous radial peaking factors in the SC CASTOR 440/84 with the reference pattern.

calculations were performed with a homogeneous pattern of power (peaking equals to 1.0).

As mentioned above, the resulting PCTs are very similar to the applicant's results. Moreover, six thermocouples were installed on the outer surface of the SC CASTOR 440/84 No. 10, and the actual temperatures on the outer surface of this cask were measured. The thermocouples were on the shielding lid and on the outer surface in various axial positions. The data obtained were compared with the COBRASFS simulation and applicant's calculations to validate COBRA-SFS model. The comparison of the measurements and calculations is summarized in Table 2 .

Based on the comparison of the applicant's calculations and to the data experimentally measured, both thermal models of SCs were validated and verified. This, in conjunction with the other validation data available, suggests that COBRA-SFS predicts the physics appropriately for calculating surface temperature and PCT and can be used for calculation of other problems and in other applications as approved by the SUJB staff. 

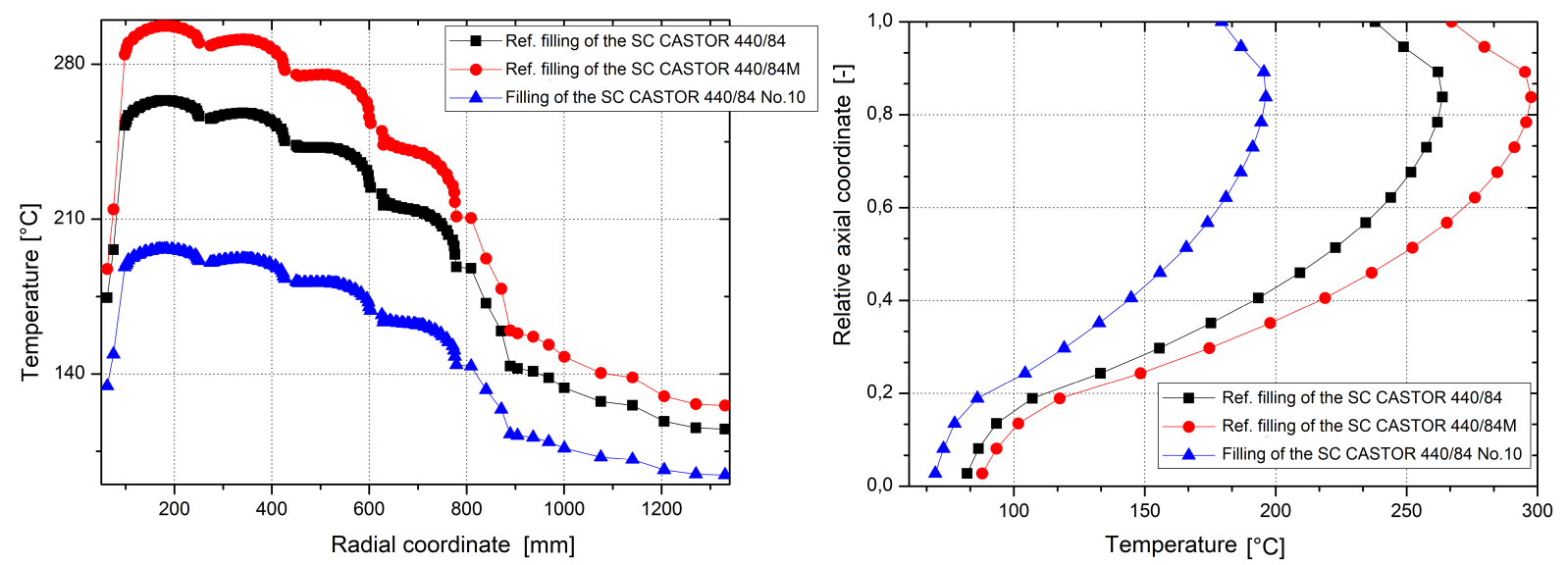

Figure 9. Radial (left) and axial (right) temperature distribution in SC CASTOR 440/84 for two reference cases and for the real SC No.10. In the case of filling the older CASTOR 440/84 with the licensed reference filling of the modified type CASTOR $440 / 84 \mathrm{M}$, the PCT will reach almost $300{ }^{\circ} \mathrm{C}$ which is more than $30{ }^{\circ} \mathrm{C}$ difference in the PCT in comparison with the CASTOR 440/84M.

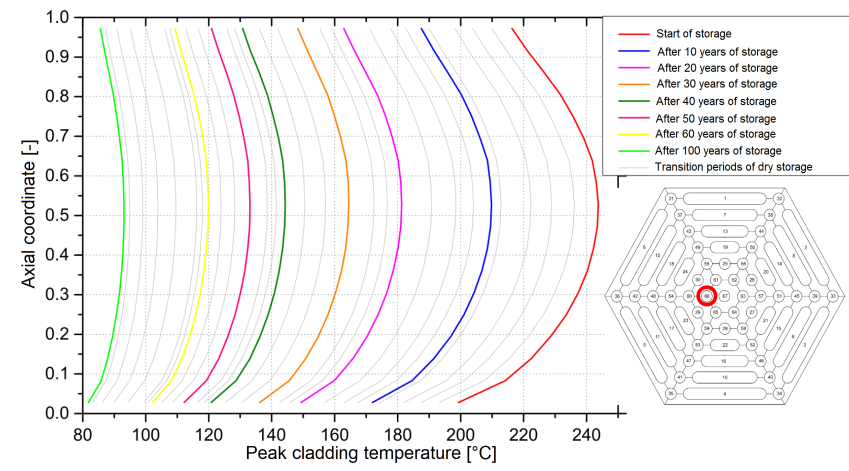

Figure 10. Axial PCT distributions for the hottest rod No.66 in fuel assembly No. 3 at different times of SNF dry storage in SC CASTOR 440/84M.

\subsection{Quasi-steady State Calculations}

COBRA-SFS can perform transient calculations but only for short transients such as drying of a SC and accidental conditions. The thermal models that were developed perform only steady-state calculations and they are not suitable for long-term transient calculations. However, there is a possibility of calculating the boundary conditions for different time frames and using them for the steady-state model. This approach was chosen for the calculation of the PCT evolution during 100 years of dry storage. Other time-dependent effects such as degradation, geometry changes, etc. were neglected.

As the source term is decreasing, the PCT is decreasing as well. Both types of SCs hold a valid license for 60 years of dry storage, but there were some suggestions by the applicant that the license period shall be lengthened in the future. The results of the PCT evolution are summarized in Figure 10. The temperature profile is similar to the original heat generation profile, but it is influenced by the natural circulation of helium that is coolest on the bottom of the SC and is reheated as it is moving upwards.

\subsection{Disposal Configuration}

The Czech Government approved a plan for opening a final disposal site for the SNF in 2065. Research and development of the project have been running for several years and brought several new ideas, including the using of the dual-purpose storage cask CASTOR for disposal purposes. This approach would significantly reduce the cost and number of manipulations of the SNF.

However, SCs CASTOR were designed, fabricated, and licensed as storage and transportation casks, and there are some doubts about using them for disposal purposes. One of the concerns is a removal of residual heat. For that purpose, several modifications were made to the original COBRA-SFS models of SC CASTOR to accommodate the conditions inside the disposal facility. The design of the disposal facility originates from Sweden [41] with horizontal placement of the storage/disposal cask CASTOR. New materials with their fundamental physical properties were implemented. The granite is assumed as a homogeneous material with no faults. Temperature boundary condition was defined on the outer surface of the granite 10 meters from SC's surface. The model of disposal configuration inside the disposal facility is illustrated in Figure 11.

The goal was to calculate the limiting cooling time necessary for sufficient cooling of the SNF. In the disposal configuration, there is a fundamental limit of $100{ }^{\circ} \mathrm{C}$ for the bentonite/SC interface. Bentonite is a special material surrounding the disposal cask that has optimal isolation and confining properties for the disposal of the SNF. However, the material must remain wet to keep the optimal characteristics and, therefore, limits the temperature on the interface: Disposal cask/Bentonite to $100^{\circ} \mathrm{C}$.

The method of semitransient calculation described in Section 5.2 was used to evaluate the maximal residual heat generation in the disposal configuration, 


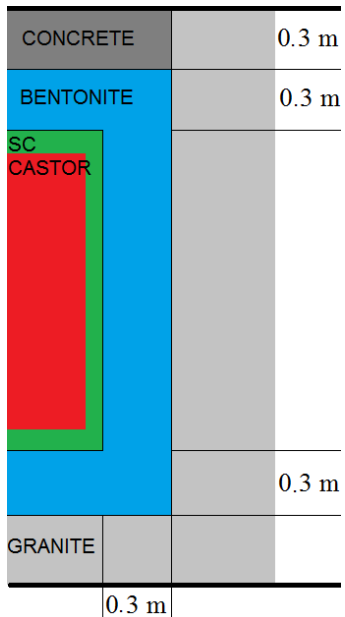

Figure 11. Model of disposal configuration based on the Swedish disposal concept with SC CASTOR horizontally disposed. SC is confined by bentonite $0.3 \mathrm{~m}$ thick in horizontal position and sealed with concrete. It is fully surrounded by granite.

which might be permitted by the SUJB in the future. The Figure 12 shows the relation between the peak temperature on the interface bentonite/SC CASTOR and the corresponding residual power of the SNF. The limiting value of the residual heat is 23 Watts per fuel assembly as shown in the graph to keep the temperature under the limit. However, it should be pointed out that the model is based on the storage configuration of the SC and only the boundary conditions were changed based on the disposal design.

\section{Summary and Conclusions}

Two types of dry storage casks have been used at the Dukovany storage facility. Every design of storage, transportation, or disposal cask must be licensed in the Czech Republic by the SUJB based on the application from the responsible utility. CFD codes have been recently widely used by applicants, but there are several disadvantages connected to the usage of such codes. For that reason, the SUJB decided to perform the independent heat removal system evaluation of SCs CASTOR using the COBRA-SFS code.

Two heat removal models: CASTOR 440/84 and CASTOR 440/84M were created and validated using experimental data and independent code-to-code validation. The presented calculations suggest that COBRA-SFS is able to accurately predict the PCT temperature which is the limiting factor for dry storage. It also confirms that the code accurately predicts cases with hexagonal geometry such as WWER fuel assemblies. The models were used to reassess the safe removal of residual heat for reference SNF patterns and the evolution of PCT during 100 years storage. In the worst case scenario, the PCT is not higher than $256.8{ }^{\circ} \mathrm{C}$ for CASTOR $440 / 84$ and $298{ }^{\circ} \mathrm{C}$ for CASTOR $440 / 84 \mathrm{M}$, which is well below the limiting value defined by the SUJB and international guides. Addi-

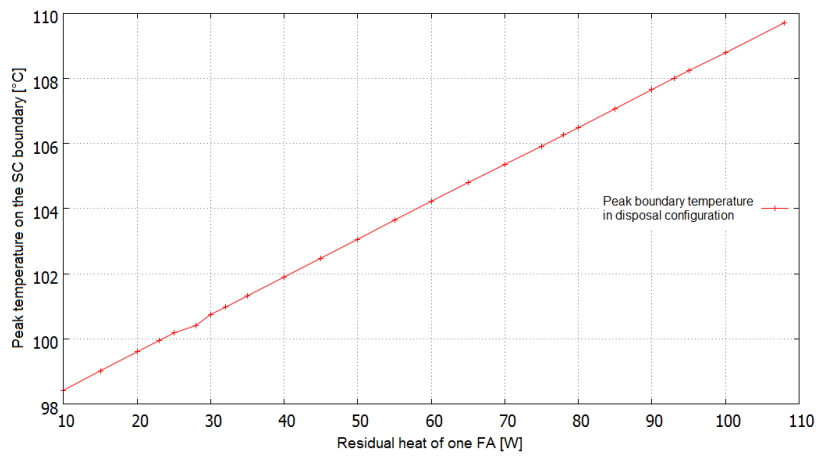

FigURE 12. Linear relation between the residual heat generated by the SNF and peak SC/bentonite interface temperature in the disposal configuration. The limiting temperature corresponds to the 23 Watts per one WWER-440 SNF assembly in homogeneous configuration of the SC CASTOR 440/84M.

tionally, these conservative limits are well above the real best-estimate PCTs. The calculation of the real pattern from the SC number 10 shows PCT below $210{ }^{\circ} \mathrm{C}$.

One of the possible solutions for final disposal is to use SCs CASTOR also as a disposal cask in the Czech Republic. The Swedish concept of disposal configuration was adopted, and the original disposal cask was replaced by the SC CASTOR. The calculation using COBRA-SFS models proved that this disposal configuration will be safe if the residual heat of one WWER-440 fuel assembly will be limited to 23 Watts. This value corresponds to 140 years of dry storage before placing SCs with SNF to the disposal facility.

\section{ACKNOWLEDGEMENTS}

The work was supported by the CTU in Prague, provided under grant number SGS16/252/OHK4/3T/14 and by the State Office for Nuclear Safety, Czech Republic.

\section{REFERENCES}

[1] J. Mahaffy, B. Chung, C. Song, et al. Best practice guidelines for the use of cfd in nuclear reactor safety applications. Tech. rep., Organisation for Economic Co-Operation and Development, Nuclear Energy Agency-OECD/NEA, Committee on the safety of nuclear installations-CSNI, Le Seine Saint-Germain, 12 boulevard des Iles, F-92130 Issy-les-Moulineaux (France), 2007.

[2] L. E. Herranz, J. Penalva, F. Feria. CFD analysis of a cask for spent fuel dry storage: Model fundamentals and sensitivity studies. Annals of Nuclear Energy 76:54-62, 2015. DOI:10.1016/j.anucene.2014.09.032.

[3] S. H. Yoo, H. C. No, H. M. Kim, E. H. Lee. Full-scope simulation of a dry storage cask using computational fluid dynamics. Nuclear Engineering and Design 240(12):4111-4122, 2010. DOI:10.1016/j.nucengdes.2010.08.009.

[4] V. Simonis, V. Ragaisis, A. Smaizys. Thermal assessment of new ignalina npp casks for spent nuclear fuel storage at some abnormal conditions. Mechanika 19(2):159-166, 2013. 
[5] M.-H. Chun, J.-W. Park. A simplified two-step thermal analysis method for Wolsung (CANDU) spent fuel dry storage canister. International Communications in Heat and Mass Transfer 20(2):185196, 1993. DOI:10.1016/0735-1933(93)90047-Y.

[6] S. H. Yoo. Thermal-hydraulic experiment and analysis for interim dry storage of spent nuclear fuel 2011.

[7] P. Bouffioux. Transportation and interim dry storage of PWR's spent fuel. EDF report. Tech. rep., HT25-C2005-192/PBF, 2005.

[8] R. R. DeVoe, K. R. Robb, S. E. Skutnik. Sensitivity analysis for best-estimate thermal models of vertical dry cask storage systems. Nuclear Engineering and Design 320:282-297, 2017.

DOI:10.1016/j.nucengdes.2017.06.005.

[9] T. E. Michener, D. R. Rector, J. M. Cuta, et al. COBRA-SFS: A thermal-hydraulic analysis code for spent fuel storage and transportation casks. PNL-10782, Pacific Northwest National Laboratory, Richland, Washington 1995.

[10] U. N. R. Commission, others. Standard review plan for spent fuel dry storage systems at a general license facility. NUREG-1536 2010.

[11] C. Storage, B. Management, D. Studies, N. Council Safety and Security of Commercial Spent Nuclear Fuel Storage:: Public Report. National Academies Press, 2006.

[12] D. R. Rector, R. A. McCann, U. P. Jenquin, et al. Castor-1C spent fuel storage cask decay heat, heat transfer, and shielding analyses. Tech. Rep. PNL-5974, Pacific Northwest Lab., Richland, WA (USA), 1986. DOI:10.2172/7174903.

[13] V. Dolecek. Comparison of uniform and non-uniform residual power of fuel assemblies in a CASTOR 440/84 container by means of COBRA-SFS Cycle 3 code. Tech. Rep. UJV-12260-T, Nuclear Research Institute Rez, 2005.

[14] M. McKinnon, J. Creer, T. Michener, et al. TN-24P PWR Spent Fuel Storage Cask Performance Testing and Analyses. Tech. rep., PNL-6054/NP-5128, Pacific Northwest Laboratory, 1986.

[15] M. A. McKinnon, J. M. Creer, C. L. Wheeler, et al. The MC-10 PWR spent fuel storage cask: Testing and analysis. Tech. Rep. EPRI-NP-5268, Pacific Northwest Lab., Richland, WA (USA); Virginia Power Co., Richmond (USA); EG and G Idaho, Inc., Idaho Falls (USA); Electric Power Research Inst., Palo Alto, CA (USA), 1987.

[16] X. Chen, N. Todreas. Thermal analysis of dry spentfuel transportation and storage casks. Transactions of the American Nuclear Society 75:367-368, 1996.

[17] I. Vasilchenko, S. Kushmanov, V. Vjalitsyn, R. Vasilchenko. Core Designs of Modern VVER Projects .

[18] I. Fluent. Fluent 6.3 users guide. Fluent documentation 2006.

[19] N. Lombardo, J. Cuta, T. Michener, et al. COBRASFS: A Thermal-Hydraulic Analysis Computer Code, Volume III: Validation Assessments. PNL-6049 3, 1986.
[20] D. R. Rector, R. McCann, U. P. Jenquin, et al. Castor-1c spent fuel storage cask decay heat, heat transfer, and shielding analyses. Tech. rep., Pacific Northwest Lab., Richland, WA (USA), 1986.

[21] D. Rector, C. Wheeler, N. Lombardo. Thermal-hydraulic analysis of spent fuel storage systems. Tech. rep., Pacific Northwest Lab., Richland, WA (USA), 1987.

[22] S. H. Yoo, H. M. Kim, H. C. No. Cfd validation of heat transfer in a spent fuel assembly. Power 99:49, 2007.

[23] T. E. Michener, D. R. Rector, J. M. Cuta. Validation of COBRA-SFS with Measured Temperature Data from Spent-Fuel Storage Casks. Nuclear Technology 199(3):350-368, 2017. DOI:10.1080/00295450.2017.1327253.

[24] X. Heng, G. Zuying, Z. Zhiwei. A numerical investigation of natural convection heat transfer in horizontal spent-fuel storage cask. Nuclear Engineering and Design 213(1):59-65, 2002.

[25] M. Wataru, H. Takeda, K. Shirai, T. Saegusa. Thermal hydraulic analysis compared with tests of full-scale concrete casks. Nuclear Engineering and Design 238(5):1213-1219, 2008.

DOI:10.1016/j.nucengdes.2007.03.036.

[26] A. Zigh, J. Solis. Computational fluid dynamics best practice guidelines in the analysis of storage dry cask. Tech. rep., WM Symposia, 1628 E. Southern Avenue, Suite 9-332, Tempe, AZ 85282 (United States), 2008.

[27] O. of Nuclear Material Safety, Safeguards. Nureg-1536: Standard review plan for spent fuel dry storage systems at a general license facility. Tech. rep., U.S. NRC, (USA), 2010.

[28] T. E. Michener, M. A. McKinnon, D. R. Rector, J. M. Creer. Thermal-hydraulic analyses of the TN-24P cask loaded with consolidated and unconsolidated spent nuclear fuel. Tech. Rep. PNL-SA-16240; CONF-8906013, Pacific Northwest Lab., Richland, WA (USA), 1989.

[29] D. Rector, T. Michener, J. Cuta. Verification and validation of cobra-sfs transient analysis capability. Tech. rep., Pacific Northwest National Lab., Richland, WA (United States), 1998.

[30] D. Rector, C. Wheeler, P. N. Laboratory, U. S. D. of Energy. COBRA-SFS Thermal Analysis of a Sealed Storage Cask for the Monitored Retrievable Storage of Spent Fuel. Pacific Northwest Laboratory, 1986.

[31] SUJB. Decree of the sujb no. 317/2002 coll. on on type approval of packaging assemblies for transport, storage and disposal of nuclear materials and radioactive substances, on type approval of ionizing radiation sources and on transport of nuclear materials and specified radioactive substances. Tech. rep., State Office for Nuclear Safety, 2002.

[32] SUJB. Act no. 18/1997 coll., on peaceful utilization of nuclear energy and ionising radiation (the atomic act) and on amendments and additions to related acts. Tech. rep., State Office for Nuclear Safety, 1997.

[33] International Atomic Energy Agency. Storage of Spent Nuclear Fuel. International Atomic Energy Agency, Vienna, 2012. OCLC: 794367550. 
[34] B. Murphy. ORIGEN-ARP cross-section libraries for magnox, advanced gas-cooled, and VVER reactor designs. United States. Department of Energy, 2004.

[35] G. Ilas, B. D. Murphy, I. C. Gauld. Overview of origen-arp and its application to vver and rbmk. TRANSACTIONS-AMERICAN NUCLEAR SOCIETY 97:601, 2007.

[36] G. Ilas, I. C. Gauld, V. Jodoin. LWR cross section libraries for ORIGEN-ARP in SCALE 5.1. Transactions of the American Nuclear Society 95:706-708, 2006.

[37] J. Vesely, M. Valach, Z. Frejtich, V. Priman. Creep properties of non-irradiated zrlnb cladding tubes under normal and abnormal storage conditions. Storage of spent fuel from power reactors p. 305, 1999.

[38] S. M. Bowman, I. C. Gauld. OrigenArp Primer: How to Perform Isotopic Depletion and Decay Calculations with SCALE/ORIGEN. Tech. Rep. ORNL/TM-
2010/43, Oak Ridge National Lab. (ORNL), Oak Ridge, TN (United States), 2010. DOI:10.2172/986788.

[39] T. E. Michener, D. R. Rector, J. M. Cuta, et al. COBRA-SFS: A thermal-hydraulic analysis code for spent fuel storage and transportation casks. Pacific Northwest Laboratory, 1995.

[40] T. E. Michener, D. R. Rector, J. M. Cuta. COBRA-SFS Thermal-Hydraulic Analysis Code for Spent-Fuel Storage and Transportation Casks: Models and Methods. Nuclear Technology 199(3):330-349, 2017. DOI:10.1080/00295450.2017.1305190.

[41] J. Andersson, K. Skagius, A. Winberg, et al. Site-descriptive modelling for a final repository for spent nuclear fuel in sweden. Environmental earth sciences 69(3):1045-1060, 2013. 